\title{
Administration of the Mitochondrial Permeability Transition Pore Inhibitor, TR040303, prior to Primary Percutaneous Coronary Intervention, Does Not Affect the Levels of Pro-Inflammatory Cytokines or Acute-Phase Proteins
}

\author{
Noreen Butt $^{\mathrm{a}, \mathrm{c}}$ Lena K. Bache-Mathiesen ${ }^{\mathrm{b}}$ Jan Erik Nordrehaug ${ }^{\mathrm{a}, \mathrm{c}}$ \\ Vegard Tuseth $^{d}$ Peter Scott Munk ${ }^{i}$ Vernon Bonarjee ${ }^{a}$ Trygve Sundby Halle

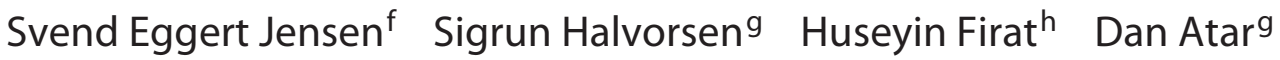 \\ Alf Inge Larsen ${ }^{\text {a, } c}$ \\ Departments of a Cardiology and ${ }^{b}$ Biostatistics, Stavanger University Hospital, Stavanger, ${ }^{\mathrm{C}}$ Department of \\ Clinical Science, University of Bergen, and d Department of Cardiology, Haukeland University Hospital, Bergen, \\ e Department of Cardiology, Oslo University Hospital Ullevål, Oslo, Norway; ${ }^{f}$ Aalborg University Hospital, Aalborg, \\ Denmark; ${ }^{9}$ Department of Cardiology, Oslo University Hospital Ullevål and University of Oslo, Oslo, Norway; \\ hFiralis SAS Huningue, Paris, France; 'Sorlandet Hospital, Kristiansand, Norway
}

\section{Keywords}

STEMI - Primary percutaneous coronary intervention · Reperfusion injury · Cytokines · Mitochondrial permeability transition pore

\begin{abstract}
Objectives: In the MITOCARE study, reperfusion injury was not prevented after administration of the mitochondrial permeability transition pore (MPTP) opening inhibitor, TRO40303, in patients with ST-segment elevation myocardial infarction (STEMI) treated with primary percutaneous coronary intervention ( $\mathrm{pPCl}$ ). The effects of TRO40303 on pro-inflammatory cytokines and acute-phase proteins were assessed. Methods: STEMI patients ( $n=163$, mean age 62 years) with chest pain within $6 \mathrm{~h}$ before admission for $\mathrm{pPCl}$ were randomized to intravenous bolus of TRO40303 $(n=83)$ or placebo $(n=80)$ prior to reperfusion. We tested whether
\end{abstract}

\section{KARGER}

(C) 2017 S. Karger AG, Basel

E-Mail karger@karger.com

www.karger.com/crd the groups differed in levels of IL-1 $\beta, I L-6, I L-10, T N F$, and high-sensitive $\mathrm{C}$-reactive protein at various time points $(0$, 12 , and $72 \mathrm{~h}$ ) after $\mathrm{PCl}$. Further, potential differences between groups in the change of biomarker levels between 0 and 72 h, 0 and 12 h, and 12 and 72 h were tested. Results: There were no statistically significant differences between the two groups, neither in levels of pro-inflammatory cytokines nor in levels of acute-phase proteins, and there were no statistically significant differences in the change of biomarker levels between the groups considering the time intervals from 0 to $72 \mathrm{~h}$, from 0 to $12 \mathrm{~h}$, and from 12 to $72 \mathrm{~h}$. Conclusion: The administration of the mPTP, TRO40303, prior to reperfusion does not alter the pharmacokinetics of pro-inflammatory cytokines or acute-phase proteins during the first $72 \mathrm{~h}$ after $\mathrm{PCl}$.

(c) 2017 S. Karger AG, Basel

Clinicaltrialsregister.eu; EudraCT number 2010-024616-33.

Noreen Butt

Department of Cardiology, Stavanger University Hospital PO Box 8100

NO-4068 Stavanger (Norway)

E-Mail noreen.butt@sus.no 


\section{Introduction}

Despite the proven success of rapid restoration of epicardial coronary blood flow with thrombolytics or primary percutaneous coronary intervention (pPCI) in patients admitted with ST-segment elevation myocardial infarction (STEMI) [1,2], additional myocardial damage may occur after reperfusion. The process known as reperfusion injury affects myocyte viability, contractile performance, arrhythmia threshold, and endothelial function [3-5]. Reperfusion injury is partly related to the effect of toxic substances released from the anoxic mitochondria after reperfusion due to opening of the mitochondrial permeability transition pore ( $\mathrm{mPTP})$, and partly related to the activation of a general myocardial inflammation [6]. Numerous adhesion molecules and inflammation mediators are expressed and/or upregulated and lead to the fixation of leukocytes to the endothelium and the cardiomyocytes [7]. Cytokines also take part in the cardioprotection cascades that act on the MPTP $[8,9]$.

The tissue injury in acute myocardial infarction (AMI) triggers inflammation. The inflammatory response is complex and may be unpredictable, partly explaining why clinical interventions against reperfusion injury have failed.

Pro-inflammatory cytokines, such as interleukin-6 (IL-6) and tumor necrosis factor (TNF), induce tissue destruction, while anti-inflammatory cytokines suppress inflammation and promote healing. Some cytokines, such as interleukin-10 (IL-10), which is found within the atheromatous plaque, are both anti-inflammatory and pro-inflammatory.
Inflammatory cytokines like TNF and IL-6 initiate dysregulation of intracellular $\mathrm{Ca}^{2+}$. TNF reduces $\mathrm{Ca}^{2+}$ sensitivity of myofibrils and inhibits expression of SERCA2a [10]. These effects seem to be inhibited by radical scavengers indicating that the negative effects of the inflammatory cytokines are partially mediated with reactive oxygen species (ROS) leaking from the hypoxic mitochondria [11].

In the MITOCARE study, administration of the mPTP opening inhibitor, TRO40303, prior to PPCI in patients with STEMI did not reduce infarct size $[12,13]$. Whether the blockage of the mitochondrial transition pore with TRO40303 has a modulating effect on levels of pro-inflammatory cytokines as well as acute-phase proteins has not previously been assessed in this population.

\section{Methods}

The MITOCARE study was a multicenter randomized, doubleblind, placebo-controlled trial carried out in 4 European countries between October 2011 and September 2013. STEMI patients $(n=$ 167) undergoing pPCI with acute chest pain within $6 \mathrm{~h}$ before admission were randomized to intravenous bolus of TRO40303 or placebo prior to reperfusion. Patients with prodromal symptoms and patients with multivessel disease were not eligible. Two patients did not meet the inclusion criteria and 2 patients in the TRO40303 group received treatment but did not undergo PCI. A total number of 163 patients were included, of whom 83 received TRO40303 and 80 received placebo (Fig. 1). Two patients in the TRO40303 group did not undergo PCI but were included in the main trial for safety analysis. The kinetics of cytokines and highsensitive C-reactive protein (hsCRP) were analyzed in 161 patients of whom 79 were in the placebo group and 82 were in the treatment

Fig. 1. Patient flow. PCI, percutaneous cor-

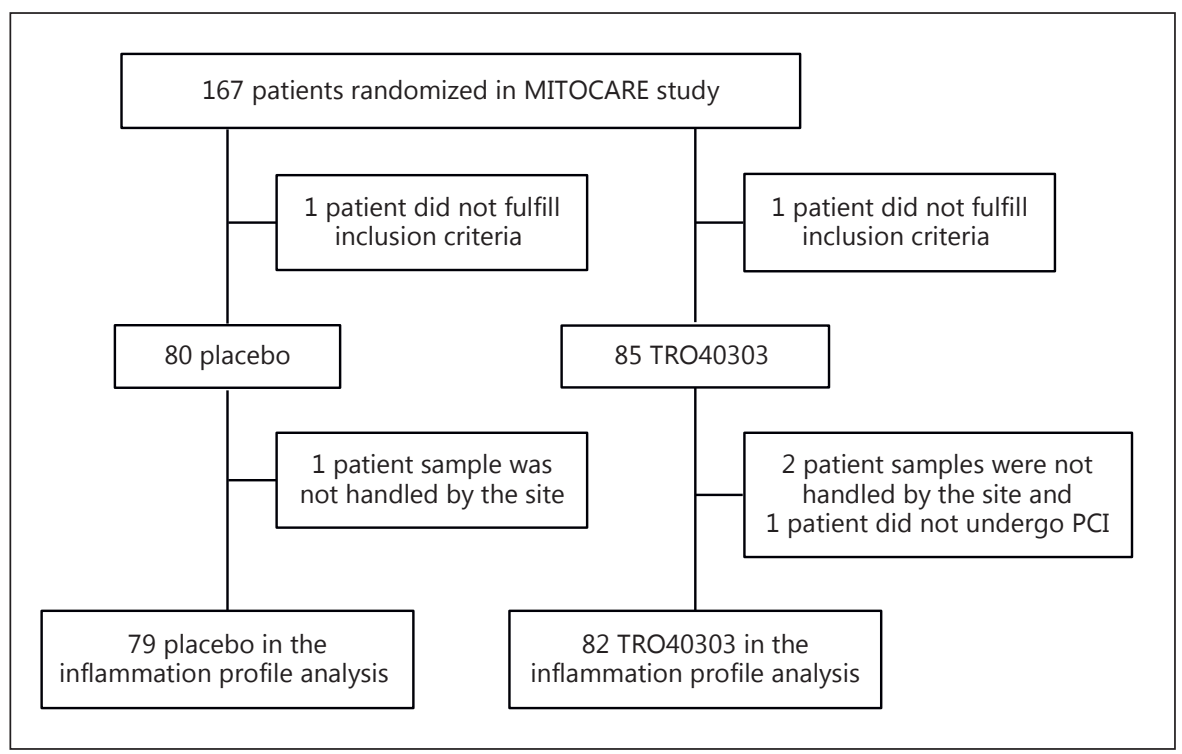
onary intervention.

Administration of TRO40303 prior to pPCI
Cardiology 2017;138:122-132

DOI: $10.1159 / 000475460$ 
Table 1. MITOCARE patient characteristics

\begin{tabular}{|c|c|c|c|c|}
\hline Variable & $\begin{array}{l}\text { Overall } \\
(n=161)\end{array}$ & $\begin{array}{l}\text { Placebo } \\
(n=79)\end{array}$ & $\begin{array}{l}\text { TRO } 40303 \\
(n=82)\end{array}$ & $p$ value $^{\mathrm{a}}$ \\
\hline Median age, years (IQR) & $62(53-70)$ & $60(53-69)$ & $63(53-71)$ & 0.536 \\
\hline Median BMI (IQR) & $27.3(25-30)$ & $26.7(24-30)$ & $27.5(25-31)$ & 0.198 \\
\hline Sex, $n(\%)$ & & & & 0.165 \\
\hline Male & $135(83.9 \%)$ & $63(79.7 \%)$ & $72(87.8 \%)$ & \\
\hline Female & $26(16.1 \%)$ & $16(20.3 \%)$ & $10(12.2 \%)$ & \\
\hline Diabetes, $n(\%)$ & & & & 0.519 \\
\hline Yes & $12(7.5 \%)$ & $7(8.9 \%)$ & $5(6.1 \%)$ & \\
\hline No & $149(92.5 \%)$ & $72(91.1 \%)$ & $77(93.9 \%)$ & \\
\hline Hypertension, $n(\%)$ & & & & 0.654 \\
\hline Yes & $47(29.2 \%)$ & $25(31.6 \%)$ & $22(26.8 \%)$ & \\
\hline No & $114(70.8 \%)$ & $54(68.4 \%)$ & $60(73.2 \%)$ & \\
\hline Smoking, $n(\%)$ & & & & 0.851 \\
\hline Yes & $67(46.2 \%)$ & $33(46.5 \%)$ & $34(45.9 \%)$ & \\
\hline No & $78(53.8 \%)$ & $38(53.5 \%)$ & $40(54.1 \%)$ & \\
\hline Stratum, $n(\%)$ & & & & 0.607 \\
\hline Anterior & $64(39.8 \%)$ & $33(41.8 \%)$ & $31(37.8 \%)$ & \\
\hline Posterior & $97(60.2 \%)$ & $46(58.2 \%)$ & $51(62.2 \%)$ & \\
\hline Killip class, $n(\%)$ & & & & 0.984 \\
\hline 1 & $112(70.4 \%)$ & $55(70.5 \%)$ & $57(70.4 \%)$ & \\
\hline $2-5$ & $47(29.6 \%)$ & $23(29.5 \%)$ & $24(29.6 \%)$ & \\
\hline
\end{tabular}

IQR, interquartile range; BMI, body mass index. ${ }^{a} p$ value results from $\chi^{2}$ tests if the variable was categorical and $t$ tests if the variable was continuous. BMI was non-normally distributed in the TRO40303 group, and therefore, the Mann-Whitney test was used instead.

group (Fig. 1). The study was in accordance with the Declaration of Helsinki, and approved by the regional ethics committees. Informed consent was obtained from all subjects.

The patient characteristics have previously been reported (Table 1) [12]. The core lab FIRALIS (Firalis SAS Huningue, Paris, France) was responsible for the blood analysis of 161 patients to determine the levels of the pro-inflammatory cytokines (interleukin-1 $\beta$ [IL-1 $\beta$ ], IL-6, IL-10, TNF) and hsCRP before reperfusion, at 12 and $72 \mathrm{~h}$ after pPCI. IL-1 $\beta$, IL-6, IL-10, and TNF levels were quantified by the use of an MSD Proinflammatory Panel I kit. Levels of hsCRP were quantified by an automated analyzer (Dimension EXL 200) from Siemens. To reduce measurement error, each cytokine was measured in duplicate at the respective time points. The repeated measures had high internal consistency for IL-6, IL-10, and TNF (Cronbach's $\alpha>0.9$, intraclass correlation coefficient $>0.9$, Appendix 1), but IL- $1 \beta$ had below the acceptable internal consistency ( $\alpha=0.458$, intraclass correlation coefficient $=$ 0.297 , Appendix 1). The mean of the repeated measures for the cytokines and hsCRP was used in all analyses.

Not all patients had measurements for each biomarker at each specified time point (Appendix 2). There were in total 4 missing values for each cytokine analyzed. The remaining missing values were nondetectable due to a result below the detection method used. Twenty patients had extreme values far beyond the expected range of the biomarker on at least one repeated measure. Extreme outliers potentially caused by blood sampling or analysis error were removed from the dataset.

\section{Statistical Analysis}

All biomarkers had right-skewed distributions according to Q-Q plots and Shapiro-Wilk tests $(p<0.05)$. Thus, to test whether the groups differed in levels of IL- $1 \beta$, IL-6, IL-10, TNF, and hsCRP at the time points 0,12 , and $72 \mathrm{~h}$, Mann-Whitney U tests were performed. Further, to find out whether groups differed in the progression of the biomarker and adjust for baseline biomarker levels, the Mann-Whitney $U$ test was repeated on the change of biomarker for the time intervals $0-72 \mathrm{~h}, 0-12 \mathrm{~h}$, and $12-72 \mathrm{~h}$. A significance level of $\alpha=0.05$ was chosen for all tests. To visualize the differences between treatment groups, boxplots were created for each biomarker. In addition, line graphs were made to show the temporal changes in the levels of each biomarker during the first $72 \mathrm{~h}$ after STEMI. The Statistical Package for the Social Sciences (SPSS, Chicago, IL, USA) v.23 was used for all tests, while R version 3.2.3 was used to create graphs.

\section{Results}

The study population consisted of 161 patients, with a mean age of 62 years (IQR: $53-70$ ), and of $83.9 \%$ men. There were no statistically significant differences in baseline characteristics between the TRO40303 and the placebo group (Table 1). Levels of IL- $1 \beta$ increased during the 
Table 2. Median (interquartile range) and $p$ values (Mann-Whitney $\mathrm{U}$ test) for each biomarker at 0,12 , and $72 \mathrm{~h}$ following PCI for placebo $(n=79)$ and TRO40303 $(n=82)$

\begin{tabular}{lrccc}
\hline Biomarker & Time & Median placebo & Median TRO40303 & $p$ value \\
\hline $\mathrm{IL}-1 \beta, \mathrm{pg} / \mathrm{mL}$ & $0 \mathrm{~h}$ & $0.022(0.008-0.022)$ & $0.025(0.012-0.045)$ & 0.521 \\
& $12 \mathrm{~h}$ & $0.028(0.005-0.067)$ & $0.024(0.005-0.050)$ & 0.524 \\
& $72 \mathrm{~h}$ & $0.026(0.006-0.051)$ & $0.039(0.015-0.093)$ & 0.183 \\
\hline $\mathrm{IL}-6, \mathrm{pg} / \mathrm{mL}$ & $0 \mathrm{~h}$ & $1.21(0.8-1.8)$ & $1.16(0.8-2.2)$ & 0.604 \\
& $12 \mathrm{~h}$ & $3.60(1.2-5.5)$ & $3.11(1.9-5.0)$ & 0.500 \\
& $72 \mathrm{~h}$ & $1.89(1.3-3.6)$ & $1.93(1.2-4.2)$ & 0.736 \\
\hline $\mathrm{IL}-10, \mathrm{pg} / \mathrm{mL}$ & $0 \mathrm{~h}$ & $1.19(0.6-2.7)$ & $0.79(0.3-2.5)$ & 0.132 \\
& $12 \mathrm{~h}$ & $0.17(0.1-0.3)$ & $0.17(0.1-0.3)$ & 0.749 \\
$\mathrm{TNF}, \mathrm{pg} / \mathrm{mL}$ & $72 \mathrm{~h}$ & $0.15(0.1-0.2)$ & $0.16(0.1-0.3)$ & 0.450 \\
\hline $\mathrm{CRP}, \mathrm{mg} / \mathrm{L}$ & $0 \mathrm{~h}$ & $6.34(4.9-7.7)$ & $6.24(5.1-7.5)$ & 0.898 \\
& $12 \mathrm{~h}$ & $6.99(5.7-8.4)$ & $6.96(5.7-8.3)$ & 0.940 \\
& $72 \mathrm{~h}$ & $7.59(6.3-9.9)$ & $8.16(6.7-9.9)$ & 0.735 \\
\hline
\end{tabular}

Table 3. Median (interquartile range) and $p$ values (Mann-Whitney $U$ test) of the change over time between 0 and $12 \mathrm{~h}$, between 0 and $72 \mathrm{~h}$, and between 12 and $72 \mathrm{~h}$ following PCI for each biomarker in placebo $(n=79)$ and TRO40303 $(n=82)$

\begin{tabular}{lcccc}
\hline Biomarker & Time interval & Median placebo & Median TRO40303 & $p$ value \\
\hline $\mathrm{IL}-1 \beta, \mathrm{pg} / \mathrm{mL}$ & $0-12 \mathrm{~h}$ & $0.0036(-0.010$ to 0.021$)$ & $0.0000(-0.016$ to 0.025$)$ & 0.608 \\
& $0-72 \mathrm{~h}$ & $0.0054(-0.025$ to 0.028$)$ & $0.0097(-0.006$ to 0.065$)$ & 0.088 \\
& $12-72 \mathrm{~h}$ & $0.0025(-0.039$ to 0.019$)$ & $0.0060(-0.014$ to 0.056$)$ & 0.151 \\
\hline $\mathrm{IL}-6, \mathrm{pg} / \mathrm{mL}$ & $0-12 \mathrm{~h}$ & $2.25(0.20-4.24)$ & $2.13(0.52-3.56)$ & 0.416 \\
& $0-72 \mathrm{~h}$ & $0.91(0.15-2.19)$ & $0.94(-0.13$ to 2.40$)$ & 0.698 \\
\hline $\mathrm{IL}-10, \mathrm{pg} / \mathrm{mL}$ & $12-72 \mathrm{~h}$ & $-0.88(-2.72$ to 0.24$)$ & $-0.81(-1.78$ to 0.42$)$ & 0.722 \\
\hline $\mathrm{TNF}, \mathrm{pg} / \mathrm{mL}$ & $0-12 \mathrm{~h}$ & $-1.053(-2.47$ to -0.17$)$ & $-0.485(-2.23$ to -0.035$)$ & 0.096 \\
& $0-72 \mathrm{~h}$ & $-1.025(-5.23$ to -0.18$)$ & $-0.665(-4.49$ to -0.040$)$ & 0.256 \\
& $12-72 \mathrm{~h}$ & $0.0075(-0.05$ to 0.07$)$ & $0.0050(-0.07$ to 0.07$)$ & 0.939 \\
\hline $\mathrm{CRP}, \mathrm{mg} / \mathrm{L}$ & $0-12 \mathrm{~h}$ & $0.617(-0.32$ to 1.44$)$ & $0.785(0.13-1.55)$ & 0.375 \\
& $0-72 \mathrm{~h}$ & $2.018(0.43-3.41)$ & $2.133(0.64-3.43)$ & 0.496 \\
& $12-72 \mathrm{~h}$ & $0.988(0.15-2.30)$ & $1.470(0.29-2.09)$ & 0.388 \\
\hline & $0-12 \mathrm{~h}$ & $2.54(0.7-5.3)$ & $2.69(1.4-5.1)$ & 0.401 \\
\hline
\end{tabular}

first $12 \mathrm{~h}$ of STEMI, but returned to baseline levels after $72 \mathrm{~h}$ (Table 2; Fig. 2a, b). Levels of IL-6 appeared to increase at $12 \mathrm{~h}$, and gradually decreased during the next $60 \mathrm{~h}$, but at this point, thus still had not returned to baseline levels (Table 2; Fig. 2c, d). From baseline to $12 \mathrm{~h}$, levels of IL-10 decreased, and between 12 and $72 \mathrm{~h}$, they re- mained stable at approximately the same value (Table 2; Fig. 2e, f). During the first $12 \mathrm{~h}$, levels of TNF increased, and from 12 to $72 \mathrm{~h}$, they increased further, but at a slower rate (Table 2; Fig. $2 \mathrm{~g}, \mathrm{~h}$ ). Levels of hsCRP increased gradually and at approximately the same rate from baseline to $72 \mathrm{~h}$ (Table 2; Fig. 2i, j). 
Fig. 2. The kinetic profile of cytokines and CRP during the first $72 \mathrm{~h}$ following PCI for TRO40303 and placebo. Shown for levels of IL-1 $\beta$ (a, b), IL-6 (c, d), IL-10 (e, f), TNF $(\mathbf{g}, \mathbf{h})$, and CRP $(\mathbf{i}, \mathbf{j})$. Round points denote the median level of the corresponding biomarker at the time measured $(0,12$, and $72 \mathrm{~h}$ ). Whiskers represent the interquartile range.

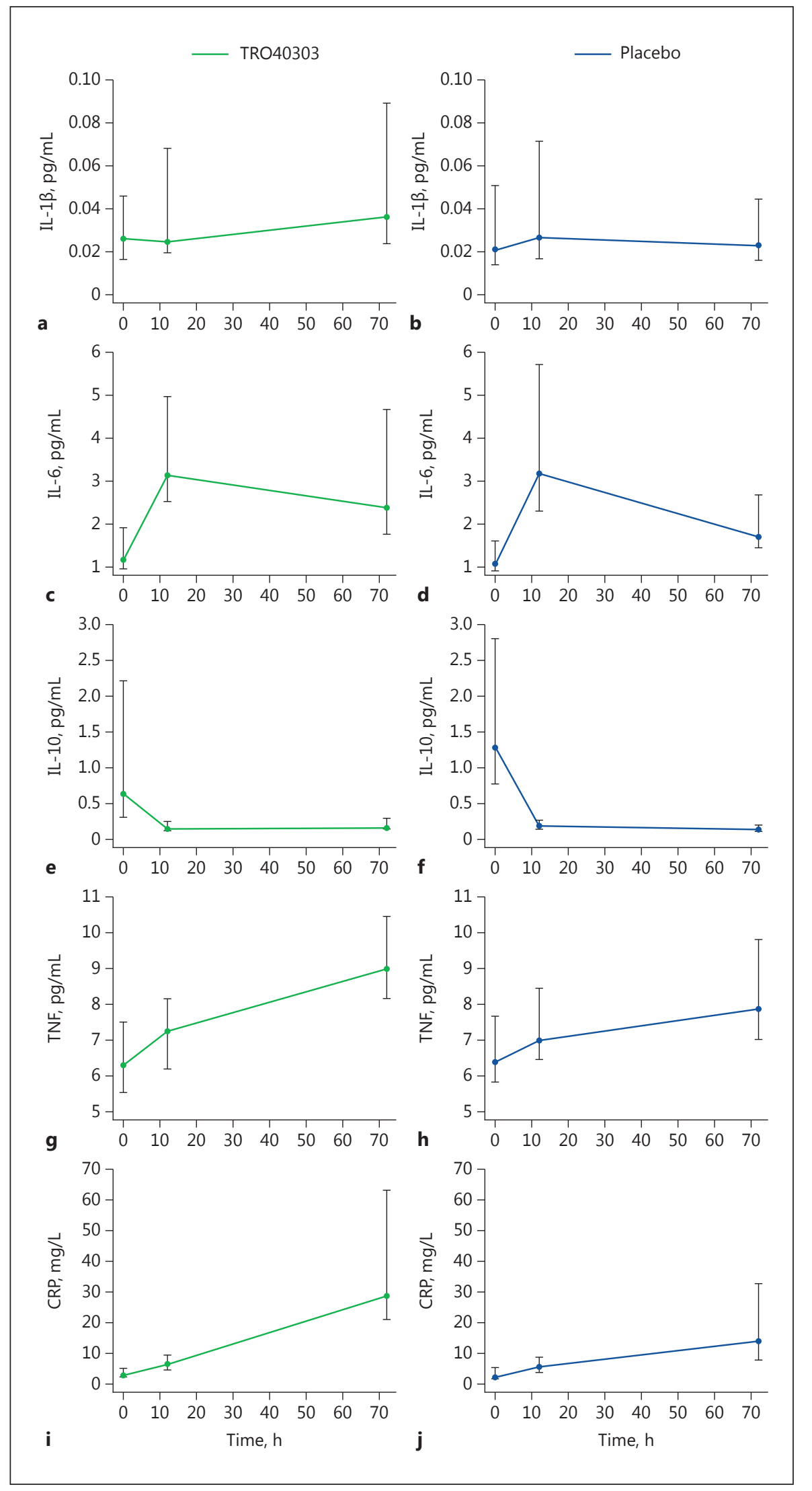

Butt et al. 


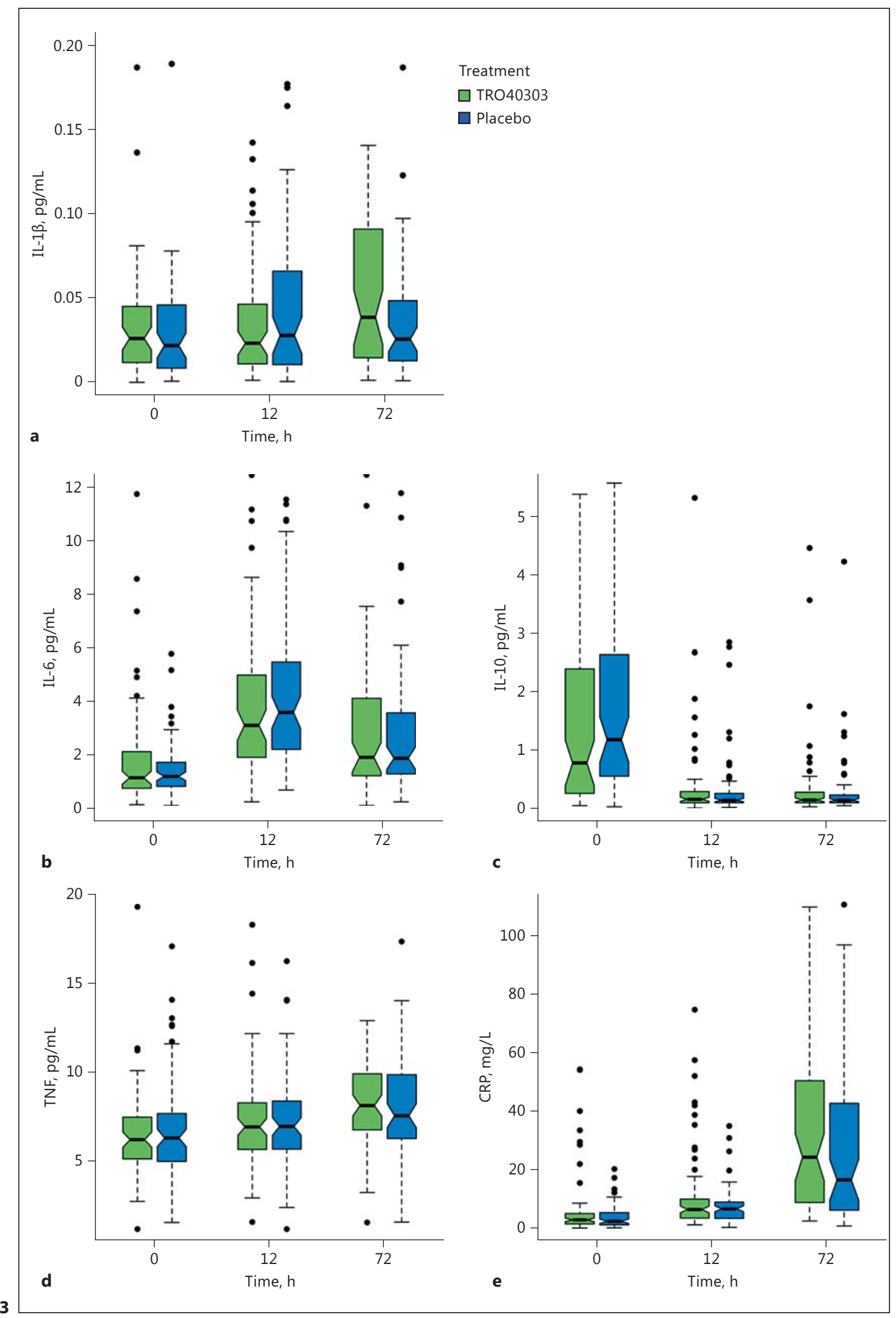

(For legend see next page.) 
There were no statistically significant differences between the two groups, neither in levels of pro-inflammatory cytokines nor in levels of hsCRP at any time point $(p>0.05$, Table 2$)$. Moreover, there were no statistically significant differences in the change of the biomarker levels for the time intervals from 0 to $72 \mathrm{~h}$, from 0 to $12 \mathrm{~h}$, and from 12 to $72 \mathrm{~h}$ between the two groups $(p>0.05$, Table 3 ). The similarity between groups is illustrated in the boxplots (Fig. 3).

\section{Discussion}

The main finding from the current substudy of the MITOCARE randomized controlled trial was that blockage of the mitochondrial transition pore had no significant effect on the temporal changes in circulating levels of the inflammatory cytokines IL-1 $\beta$, IL-6, IL-10, and TNF or the acute-phase protein, hsCRP, in STEMI patients treated with pPCI during the first $72 \mathrm{~h}$ after PCI. The inability of TRO40303 to modulate inflammation seems consistent with the lack of cardioprotective effects during the reperfusion period in the main trial [12].

The reperfusion injury which occurs after the restoration of the epicardial blood flow plays a major role in the development of infarct size. The reperfusion injury cascade is thus a complex interplay between several mechanisms ending up with inflammation and cell death.

Pharmacological interventions targeting various mechanisms like calcium channel blockers, anti-inflammatory agents such as pexelizumab and modulators of the MPTP have all failed in reducing reperfusion injury [14-17].

The sudden death of myocardial cells results in activation of the immune system that plays an important role in the acute phase and in the postinfarction reparatory phase. Different pathways in the immune system are involved in the cardiac repair and remodeling process. The activated complement cascade results in the activation of TNF and cytokine induction. IL- $1 \beta$ and IL- 6 play an important role in the damaged myocardium. IL- 6 stimulates the release of CRP from the liver, which also promotes

Fig. 3. Boxplots illustrating the differences between TRO40303 and placebo in levels of pro-inflammatory cytokines and CRP during the first $72 \mathrm{~h}$ following PCI. The difference is shown for IL- $1 \beta$ (a), IL-6 (b), IL-10 (c), TNF (d), and CRP (e). Notches represent the confidence interval around the median. Overlapping notches indicate nonsignificant differences between groups. inflammation, and high levels are associated with negative remodeling and adverse outcome after AMI $[18,19]$. In addition, reparative processes are activated following AMI to stimulate healing of the infarcted myocardium [20]. Pharmacological intervention targeted to modify inflammation has so far failed to prevent left ventricular remodeling [21].

\section{The Role of Specific Interleukins in STEMI}

Our choice of inflammatory markers in this study has been extensively evaluated in experimental studies of myocardial infarction. It has been documented that levels of the pro-inflammatory cytokines IL-1 $\beta$, IL-6, and TNF are upregulated and are of prognostic significance [21, 22]. Moreover, several studies have shown involvement of inflammatory mediators in progressive myocyte loss caused by necrosis and/or apoptosis, suggesting that these cytokines are involved in the progression of cardiac remodeling [23]. This is further reinforced by the findings of a significant correlation between IL- 6 and baseline NTpro-BNP as documented in the APEX AMI study [24]. In the current study, there was an increase in levels of IL-6 and TNF during the first hours after PCI consistent with earlier findings. The hsCRP levels also increased up to a maximum and followed the increase in levels of IL- 6 and TNF.

IL- 6 and IL- $1 \beta$ are pro-inflammatory while other cytokines are important to promote myocardial salvage. IL10 downregulates the inflammatory response in AMI. So far, experimental data are ambiguous, showing both protective and negative effects of IL-10. One experimental model has shown an important suppressive role of IL-10 that improves left ventricular function and remodeling by suppressing matrix metalloproteinase- 9 and thus inhibiting fibrosis [25]. IL-10 and pro-inflammatory-resolving lipid mediators have been identified as inhibitors of the postinfarction inflammatory reaction [26]. So far, no clinical data exist on the role of IL-10 in STEMI patients treated with pPCI. Inhibition of MPTP in our study did not show any significant difference in the temporal levels of IL-10.

Levels of IL-1 $\beta$ after STEMI revascularized by pPCI have previously been shown to have a strong association with impaired myocardial function and infarct size assessed by cardiac magnetic resonance imaging after 1 year [27]. The mechanisms are unclear, but it has been shown that IL-1 $\beta$ is involved in the increased proliferation of bone marrow hematopoietic stem cells after a myocardial infarction and by inhibiting the IL- $1 \beta$ there is a possibility to reduce infarct size [28]. In our study popula-
128

Cardiology 2017;138:122-132

DOI: $10.1159 / 000475460$
Butt et al. 
tion, treatment with TRO40303 did not have any statistically significant effect on the circulating levels of IL-1 $\beta$, indicating that the substance did not modulate the inflammation.

TNF is upregulated in AMI [29]. This cytokine is proinflammatory, but it can also promote healing by regulating the postinfarction remodeling process [30]. The action of TNF is decided by binding to two different receptors that cause cardiac injury or protect cardiomyocytes from apoptosis [31]. Binding to TNF receptor 1 leads to myocardial cell death, but the role of TNF receptor 2 is unclear. There is only one small clinical trial to our knowledge on 26 STEMI patients that investigated the effect of blocking TNF. The authors concluded that blockage of TNF did not affect the myocardial salvage [32]. Our substudy showing no effect of TRO40303 on circulating levels of circulating TNF is, therefore, not unexpected, and in accordance with results of the main study.

\section{Mitochondrial Dysfunction}

The major sources of ROS in the ischemic-reperfused myocardium are the mitochondria, xanthine oxidase, and phagocyte-derived nicotinamide adenine dinucleotide phosphate oxidase [33-35]. ROS stimulate the production of inflammatory cytokines and inversely, inflammatory cytokines stimulate ROS formation [36]. However, circulating levels of biomarkers may not necessarily reflect the accurate changes in myocardial levels. The phenomenon of mitochondrial permeability transition was detected in studies by Hunter and Haworth [37-40] in the late 1970s and was confirmed in the late 1980s by Crompton and colleagues [41-43]. The calcium overload as a result of ROS generation led to necrosis of the cardiac myocytes mediated by increased permeability of the mitochondrial membrane. The mitochondrial metabolism is depressed in STEMI resulting in a reduced level of adenosine triphosphate and increased oxidative stress with formation of ROS. The MPTP opens in response to the calcium overload that occurs in the ischemic cardiomyocytes after reperfusion. The opening of $\mathrm{mPTP}$ can be modulated directly by different pharmacologic agents, for example, cyclosporine or indirectly for instance by preconditioning [44]. In vitro studies have shown that the blockage of the MPTP in ischemic cardiomyocytes resulted in reduced levels of oxidative stress [45]. So far, 5 randomized trials have investigated the effect of cyclosporine on reperfusion injury. A small study carried out by Piot et al. [46] showed a reduction in infarct size in patients that were treated with cyclosporine before PCI. On the other hand, Cung et al. [47] failed to show any benefit of

Administration of TRO40303 prior to pPCI administering intravenous cyclosporine to inhibit the opening of MPTP in STEMI patients undergoing primary PCI $[47,48]$. Additionally, cyclosporine treatment before thrombolysis in another study population did not show any beneficial effects [49]. There may be several reasons why inhibition of MPTP by TRO40303 was not achieved in our study.

TRO40303, a novel substance, modulates the MPTP by binding to the mitochondrial translocator protein at the cholesterol site. Thereby, it reduces mitochondrial-mediated cell death by blocking the $\mathrm{mPTP}$, which leads to reduced levels of ROS in an experimental model of myocardial infarction [50]. TRO40303 has been shown to reduce infarct size when it is administered before reperfusion. The reduction in infarct size is related to the reduction in factors released by the mitochondria into the cytoplasm contributing to apoptosis and cell death. Effective inhibition of the mitochondrial transition pore should thus theoretically reduce the levels of pro-inflammatory cytokines. However, this did not occur in our study. Several other explanations are possible.

\section{Drug Dose}

The evaluation of expected active dose of TRO40303 in humans was carried out in a small selected population of 72 healthy males and postmenopausal and hysterectomized females [51]. A sublethal dose of TRO40303 has also been tested in an experimental hepatitis model where the authors showed a significant reduction in mortality [45]. The dose chosen in the MITOCARE trial might have been inadequate to achieve the optimal delaying of the mPTP opening and higher dosage could be essential in order to reduce oxidative stress in the ischemic reperfused cardiomyocytes more efficiently.

\section{Clinical versus Experimental AMI}

TRO40303 administration alone did not show promising results in our population, and this lack of clinical effect was accompanied by unchanged levels of cytokines. We could explain our neutral findings by the difference in the pathophysiology of an acute STEMI in an experimental model compared to STEMI due to a plaque rupture in a clinical setting. The rupture of a coronary plaque results in a systemic inflammatory response due to myocardial ischemia. In addition, the reperfusion itself results in marked immediate accumulation of leukocytes, mainly neutrophils into the ischemic myocardial area during the first $6 \mathrm{~h}$ [52]. In addition, endothelial cells and platelets are involved in the inflammatory reaction in the clinical setting. Since different mechanisms are involved in

Cardiology 2017;138:122-132

DOI: $10.1159 / 000475460$ 
reperfusion injury, it could be more appropriate to intervene on several levels in the reperfusion cascade [53]. Simultaneous inhibition of different inflammatory pathways could affect the outcome. Targeting both the MPTP and improving plaque stability could be a strategy. Blocking IL-6, known to destabilize plaque in acute coronary syndromes, with the IL- 6 receptor monoclonal antibody, tocilizumab, that also targets the mitochondria, has been shown to reduce infarct size in patients with non-ST-segment elevation myocardial infarction [54].

\section{Time}

The mean time between pain and PCI was reported to be median, minimum and maximum at 180,60, and 2,880 min, respectively, indicating very fast reperfusion limiting the infarct size. Whether TRO40303 would have been more efficient in reducing infarct size in patients that do not achieve rapid reperfusion is still a question. Larger infarcts show more negative remodeling and would perhaps gain benefit from mPTP inhibition by TRO40303. A clinical trial with TRO40303 performed in patients whom, due to geographical location, arrive late for mechanical reperfusion by percutaneous techniques might enlighten this issue. Thrombolysis is still an option for patients living in rural areas with long transport distances to PCI centers. One might speculate if administration of TRO40303 in addition to thrombolysis in these patients might show positive results in reducing reperfusion injury.

\section{Conclusion}

Administration of the mitochondrial transition pore inhibitor, TRO40303, had no statistically significant effect on the temporal changes in the levels of the circulating cytokines IL- $1 \beta$, IL- 6 , IL-10, and TNF or the acutephase protein, hsCRP, in STEMI patients treated with pPCI during the first $72 \mathrm{~h}$ following PCI.

\section{Acknowledgments}

We are grateful for the participation of study personnel in the MITOCARE study, the core lab FIRALIS for the biomarker analysis, and the patients taking part in the project. We also appreciate the help of study nurse, Jorunn Nilsen, for her participation in the local organization of the trial. The authors thank F. Hoffmann-La Roche Ltd. for full access to the database after their acquisition of Trophos. The MITOCARE project is supported by the European Union under the 7th Framework Programme for RTD - Project MITOCARE - Grant Agreement HEALTH - 2010-26-261034.

\section{Conflict of Interest}

N.B., L.K.B.-M., J.E.N., V.T., P.S.M., V.B., H.F, T.S.H., S.E.J., S.H., and A.I.L. do not have any conflicts of interest. D.A. received honoraria as trial leader from the EU-FP7 grant No. H - 2010-26261034. No other conflicts of interest are declared.

\section{Appendix 1}

Internal Consistency between Repeated Measures of Each Cytokine

\begin{tabular}{lll}
\hline Biomarker & Cronbach $\alpha$ & $\begin{array}{l}\text { Intraclass correlation } \\
\text { coefficient }\end{array}$ \\
\hline IL-1 $\beta, p g / m L$ & 0.458 & 0.297 \\
IL-6, pg/mL & 0.995 & 0.991 \\
IL-10, pg/mL & 0.991 & 0.982 \\
TNF, pg/mL & 0.973 & 0.947 \\
\hline
\end{tabular}

\section{Appendix 2}

Number of Missing Values for Each Biomarker at 0, 12, and $72 \mathrm{~h}$ following PCI for 161 Patients

\begin{tabular}{lcc}
\hline Biomarker & Time, h & Missing \\
\hline IL-1 $\beta, p g / m L$ & 0 & $37(23 \%)$ \\
& 12 & $30(19 \%)$ \\
& 72 & $50(31 \%)$ \\
\hline IL-6, pg/mL & 0 & $8(5 \%)$ \\
& 12 & $14(9 \%)$ \\
IL-10, pg/mL & 72 & $21(13 \%)$ \\
& 0 & $14(9 \%)$ \\
& 12 & $10(6 \%)$ \\
TNF, pg/mL & 72 & $18(11 \%)$ \\
& 0 & $8(5 \%)$ \\
& 12 & $8(5 \%)$ \\
CRP, mg/L & 72 & $20(12 \%)$ \\
& 0 & $5(3 \%)$ \\
& 12 & $25(15 \%)$ \\
\hline
\end{tabular}

Butt et al. 


\section{References}

1 Boersma E, Maas AC, Deckers JW, Simoons ML: Early thrombolytic treatment in acute myocardial infarction: reappraisal of the golden hour. Lancet 1996;348:771-775.

2 Keeley EC, Boura JA, Grines CL: Primary angioplasty versus intravenous thrombolytic therapy for acute myocardial infarction: a quantitative review of 23 randomised trials. Lancet 2003;361:13-20.

3 Reffelmann T, Kloner RA: The "no-reflow" phenomenon: basic science and clinical correlates. Heart 2002;87:162-168.

4 Ibanez B, Heusch G, Ovize M, Van de Werf F: Evolving therapies for myocardial ischemia/ reperfusion injury. J Am Coll Cardiol 2015; 65:1454-1471.

5 Heusch G, Gersh BJ: The pathophysiology of acute myocardial infarction and strategies of protection beyond reperfusion: a continual challenge. Eur Heart J 2017;38:774-784.

6 Hausenloy DJ, Botker HE, Engstrom T, Erlinge D, Heusch G, Ibanez B, Kloner RA, Ovize M, Yellon DM, Garcia-Dorado D: Targeting reperfusion injury in patients with STsegment elevation myocardial infarction: trials and tribulations. Eur Heart J 2017;38:935941.

7 Monassier JP: Reperfusion injury in acute myocardial infarction. From bench to cath lab. Part I: basic considerations. Arch Cardiovasc Dis 2008; 101:491-500.

8 Hausenloy DJ, Erik Botker H, Condorelli G, Ferdinandy P, Garcia-Dorado D, Heusch G, Lecour S, van Laake LW, Madonna R, RuizMeana M, Schulz R, Sluijter JP, Yellon DM, Ovize M: Translating cardioprotection for patient benefit: position paper from the Working Group of Cellular Biology of the Heart of the European Society of Cardiology. Cardiovasc Res 2013;98:7-27.

9 Kloner RA: Current state of clinical translation of cardioprotective agents for acute myocardial infarction. Circ Res 2013;113:451463.

10 Oral H, Dorn GW 2nd, Mann DL: Sphingosine mediates the immediate negative inotropic effects of tumor necrosis factor-alpha in the adult mammalian cardiac myocyte. J Biol Chem 1997;272:4836-4842.

11 Cailleret M, Amadou A, Andrieu-Abadie N, Nawrocki A, Adamy C, Ait-Mamar B, Rocaries F, Best-Belpomme M, Levade T, Pavoine $\mathrm{C}$, Pecker F: $\mathrm{N}$-acetylcysteine prevents the deleterious effect of tumor necrosis factor-(alpha) on calcium transients and contraction in adult rat cardiomyocytes. Circulation 2004; 109:406-411.

12 Atar D, Arheden H, Berdeaux A, Bonnet JL, Carlsson M, Clemmensen P, Cuvier V, Danchin N, Dubois-Rande JL, Engblom H, Erlinge D, Firat H, Halvorsen S, Hansen HS, Hauke W, Heiberg E, Koul S, Larsen AI, Le Corvoisier P, Nordrehaug JE, Paganelli F, Pruss RM, Rousseau H, Schaller S, Sonou G, Tuseth V, Veys J, Vicaut E, Jensen SE: Effect of intravenous TRO40303 as an adjunct to primary percutaneous coronary intervention for acute ST-elevation myocardial infarction: MITOCARE study results. Eur Heart J 2015; 36:112-119.

13 Rationale and design of the "MITOCARE" Study: a phase II, multicenter, randomized, double-blind, placebo-controlled study to assess the safety and efficacy of TRO40303 for the reduction of reperfusion injury in patients undergoing percutaneous coronary intervention for acute myocardial infarction. Cardiology 2012;123:201-207.

14 Theroux P, Gregoire J, Chin C, Pelletier G, de Guise $\mathrm{P}$, Juneau M: Intravenous diltiazem in acute myocardial infarction. Diltiazem as adjunctive therapy to activase (DATA) trial. J Am Coll Cardiol 1998;32:620-628.

15 Armstrong PW, Granger CB, Adams PX, Hamm C, Holmes D Jr, O'Neill WW, Todaro TG, Vahanian A, Van de Werf F: Pexelizumab for acute ST-elevation myocardial infarction in patients undergoing primary percutaneous coronary intervention: a randomized controlled trial. JAMA 2007;297:43-51.

16 Early administration of intravenous magnesium to high-risk patients with acute myocardial infarction in the Magnesium in Coronaries (MAGIC) Trial: a randomised controlled trial. Lancet 2002;360:1189-1196.

17 Atar D, Huber K, Rupprecht HJ, Kopecky SL, Schwitter J, Theek C, Brandl K, Henning R, Geudelin B: Rationale and design of the "F.I.R.E." study. A multicenter, double-blind, randomized, placebo-controlled study to measure the effect of FX06 (a fibrin-derived peptide Bbeta[15-42]) on ischemia-reperfusion injury in patients with acute myocardial infarction undergoing primary percutaneous coronary intervention. Cardiology 2007;108: 117-123.

18 Takahashi T, Anzai T, Kaneko H, Mano Y, Anzai A, Nagai T, Kohno T, Maekawa Y, Yoshikawa T, Fukuda K, Ogawa S: Increased Creactive protein expression exacerbates left ventricular dysfunction and remodeling after myocardial infarction. Am J Physiol 2010; 299:H1795-H1804.

19 Anzai T, Yoshikawa T, Shiraki H, Asakura Y, Akaishi M, Mitamura H, Ogawa S: C-reactive protein as a predictor of infarct expansion and cardiac rupture after a first Q-wave acute myocardial infarction. Circulation 1997;96: 778-784.

20 Frangogiannis NG: The immune system and the remodeling infarcted heart: cell biological insights and therapeutic opportunities. J Cardiovasc Pharmacol 2014;63:185-195.

21 Herskowitz A, Choi S, Ansari AA, Wesselingh $S$ : Cytokine mRNA expression in postischemic/reperfused myocardium. Am J Pathol 1995; 146:419-428.

22 Dewald O, Ren G, Duerr GD, Zoerlein M, Klemm C, Gersch C, Tincey S, Michael LH, Entman ML, Frangogiannis NG: Of mice and dogs: species-specific differences in the inflammatory response following myocardial infarction. Am J Pathol 2004; 164:665-677.

23 Herder C, Baumert J, Thorand B, Martin S, Lowel H, Kolb H, Koenig W: Chemokines and incident coronary heart disease: results from the MONICA/KORA Augsburg case-cohort study, 1984-2002. Arterioscler Thromb Vasc Biol 2006;26:2147-2152.

24 van Diepen S, Roe MT, Lopes RD, Stebbins A, James S, Newby LK, Moliterno DJ, Neumann FJ, Ezekowitz JA, Mahaffey KW, Hochman JS, Hamm CW, Armstrong PW, Theroux P, Granger CB: Baseline NT-proBNP and biomarkers of inflammation and necrosis in patients with ST-segment elevation myocardial infarction: insights from the APEX-AMI trial. J Thromb Thrombolysis 2012;34:106-113.

25 Krishnamurthy P, Rajasingh J, Lambers E, Qin G, Losordo DW, Kishore R: IL-10 inhibits inflammation and attenuates left ventricular remodeling after myocardial infarction via activation of STAT3 and suppression of HuR. Circ Res 2009;104:e9-e18.

26 Frangogiannis NG: The inflammatory response in myocardial injury, repair, and remodelling. Nat Rev Cardiol 2014;11:255-265.

27 Orn S, Ueland T, Manhenke C, Sandanger O, Godang K, Yndestad A, Mollnes TE, Dickstein K, Aukrust P: Increased interleukin1 beta levels are associated with left ventricular hypertrophy and remodelling following acute ST segment elevation myocardial infarction treated by primary percutaneous coronary intervention. J Intern Med 2012;272:267-276.

28 Sager HB, Heidt T, Hulsmans M, Dutta P, Courties G, Sebas M, Wojtkiewicz GR, Tricot B, Iwamoto Y, Sun Y, Weissleder R, Libby P, Swirski FK, Nahrendorf M: Targeting interleukin-1beta reduces leukocyte production after acute myocardial infarction. Circulation 2015;132:1880-1890.

29 Schulz R, Heusch G: Tumor necrosis factoralpha and its receptors 1 and 2: Yin and Yang in myocardial infarction? Circulation 2009; 119:1355-1357.

30 Skyschally A, Gres P, Hoffmann S, Haude M, Erbel R, Schulz R, Heusch G: Bidirectional role of tumor necrosis factor-alpha in coronary microembolization: progressive contractile dysfunction versus delayed protection against infarction. Circ Res 2007;100:140-146.

31 Hamid T, Gu Y, Ortines RV, Bhattacharya C, Wang G, Xuan Y-T, Prabhu SD: Divergent tumor necrosis factor receptor-related remodeling responses in heart failure: role of nuclear factor- $\kappa \mathrm{B}$ and inflammatory activation. Circulation 2009;119:1386-1397.

32 Padfield GJ, Din JN, Koushiappi E, Mills NL, Robinson SD, Cruden Nle M, Lucking AJ, Chia S, Harding SA, Newby DE: Cardiovascular effects of tumour necrosis factor alpha antagonism in patients with acute myocardial infarction: a first in human study. Heart 2013; 99:1330-1335.
Administration of TRO40303 prior to pPCI
Cardiology 2017;138:122-132

DOI: $10.1159 / 000475460$ 
33 Waypa GB, Marks JD, Mack MM, Boriboun C, Mungai PT, Schumacker PT: Mitochondrial reactive oxygen species trigger calcium increases during hypoxia in pulmonary arterial myocytes. Circ Res 2002;91:719-726.

34 Duilio C, Ambrosio G, Kuppusamy P, DiPaula A, Becker LC, Zweier JL: Neutrophils are primary source of $\mathrm{O}_{2}$ radicals during reperfusion after prolonged myocardial ischemia. Am J Physiol Heart Circ Physiol 2001; 280:H2649-H2657.

35 Scarabelli T, Stephanou A, Rayment N, Pasini E, Comini L, Curello S, Ferrari R, Knight R, Latchman D: Apoptosis of endothelial cells precedes myocyte cell apoptosis in ischemia/ reperfusion injury. Circulation 2001;104: 253-256.

36 Nakamura K, Fushimi K, Kouchi H, Mihara K, Miyazaki M, Ohe T, Namba M: Inhibitory effects of antioxidants on neonatal rat cardiac myocyte hypertrophy induced by tumor necrosis factor-alpha and angiotensin II. Circulation 1998;98:794-799.

37 Haworth RA, Hunter DR: The $\mathrm{Ca}^{2+}$-induced membrane transition in mitochondria. II. Nature of the $\mathrm{Ca}^{2+}$ trigger site. Arch Biochem Biophys 1979;195:460-467.

38 Hunter DR, Haworth RA, Southard JH: Relationship between configuration, function, and permeability in calcium-treated mitochondria. J Biol Chem 1976;251:5069-5077.

39 Hunter DR, Haworth RA: The $\mathrm{Ca}^{2+}$-induced membrane transition in mitochondria. III. Transitional $\mathrm{Ca}^{2+}$ release. Arch Biochem Biophys 1979;195:468-477.

40 Hunter DR, Haworth RA: The $\mathrm{Ca}^{2+}$-induced membrane transition in mitochondria. I. The protective mechanisms. Arch Biochem Biophys 1979;195:453-459.

41 Crompton M, Costi A, Hayat L: Evidence for the presence of a reversible $\mathrm{Ca}^{2+}$-dependent pore activated by oxidative stress in heart mitochondria. Biochem J 1987;245:915-918.
42 Crompton M, Costi A: Kinetic evidence for a heart mitochondrial pore activated by $\mathrm{Ca}^{2+}$, inorganic phosphate and oxidative stress. A potential mechanism for mitochondrial dysfunction during cellular $\mathrm{Ca}^{2+}$ overload. Eur J Biochem 1988;178:489-501.

43 Al-Nasser I, Crompton M: The reversible $\mathrm{Ca}^{2+}$-induced permeabilization of rat liver mitochondria. Biochem J 1986;239:19-29.

44 Halestrap AP: A pore way to die: the role of mitochondria in reperfusion injury and cardioprotection. Biochem Soc Trans 2010;38: 841-860.

45 Schaller S, Michaud M, Latyszenok V, Robert F, Hocine M, Arnoux T, Gabriac M, Codoul $\mathrm{H}$, Bourhane A, de Bellefois IC, Afxantidis J, Pruss RM: TRO40303, a mitochondrial-targeted cytoprotective compound, provides protection in hepatitis models. Pharmacol Res and Perspectives 2015;3:e00144.

46 Piot $\mathrm{C}$, Croisille $\mathrm{P}$, Staat $\mathrm{P}$, Thibault $\mathrm{H}$, Rioufol G, Mewton N, Elbelghiti R, Cung TT, Bonnefoy E, Angoulvant D, Macia C, Raczka F, Sportouch C, Gahide G, Finet G, AndreFouet X, Revel D, Kirkorian G, Monassier JP, Derumeaux G, Ovize M: Effect of cyclosporine on reperfusion injury in acute myocardial infarction. N Engl J Med 2008;359: 473-481.

47 Cung TT, Morel O, Cayla G, Rioufol G, Garcia-Dorado D, Angoulvant D, BonnefoyCudraz E, Guerin P, Elbaz M, Delarche N, Coste P, Vanzetto G, Metge M, Aupetit JF, Jouve B, Motreff P, Tron C, Labeque JN, Steg PG, Cottin Y, Range G, Clerc J, Claeys MJ, Coussement P, Prunier F, Moulin F, Roth O, Belle L, Dubois P, Barragan P, Gilard M, Piot C, Colin P, De Poli F, Morice MC, Ider O, Dubois-Rande JL, Unterseeh T, Le Breton H, Beard T, Blanchard D, Grollier G, Malquarti V, Staat P, Sudre A, Elmer E, Hansson MJ, Bergerot C, Boussaha I, Jossan C, Derumeaux G, Mewton N, Ovize M: Cyclosporine before PCI in patients with acute myocardial infarction. N Engl J Med 2015; 373:1021-1031.
48 Monassier L, Ayme-Dietrich E, AubertinKirch G, Pathak A: Targeting myocardial reperfusion injuries with cyclosporine in the CIRCUS Trial - pharmacological reasons for failure. Fundam Clin Pharmacol 2016;30: 191-193.

49 Ghaffari S, Kazemi B, Toluey M, Sepehrvand $\mathrm{N}$ : The effect of prethrombolytic cyclosporine-A injection on clinical outcome of acute anterior ST-elevation myocardial infarction. Cardiovasc Ther 2013;31:e34-e39.

50 Schaller S, Paradis S, Ngoh GA, Assaly R, Buisson B, Drouot C, Ostuni MA, Lacapere JJ, Bassissi F, Bordet T, Berdeaux A, Jones SP, Morin D, Pruss RM: TRO40303, a new cardioprotective compound, inhibits mitochondrial permeability transition. J Pharmacol Exp Ther 2010;333:696-706.

51 Le Lamer S, Paradis S, Rahmouni H, Chaimbault C, Michaud M, Culcasi M, Afxantidis J, Latreille M, Berna P, Berdeaux A, Pietri S, Morin D, Donazzolo Y, Abitbol JL, Pruss RM, Schaller S: Translation of TRO40303 from myocardial infarction models to demonstration of safety and tolerance in a randomized Phase I trial. J Transl Med 2014;12:38.

52 Smith EF 3rd, Egan JW, Bugelski PJ, Hillegass LM, Hill DE, Griswold DE: Temporal relation between neutrophil accumulation and myocardial reperfusion injury. Am J Physiol 1988; 255:H1060-H1068.

53 Heusch G, Rassaf T: Time to give up on cardioprotection? A critical appraisal of clinical studies on ischemic pre-, post-, and remote conditioning. Circ Res 2016;119:676-695.

54 Kleveland O, Kunszt G, Bratlie M, Ueland T, Broch K, Holte E, Michelsen AE, Bendz B, Amundsen BH, Espevik T, Aakhus S, Damås JK, Aukrust P, Wiseth R, Gullestad L: Effect of a single dose of the interleukin- 6 receptor antagonist tocilizumab on inflammation and troponin $\mathrm{T}$ release in patients with non-STelevation myocardial infarction: a doubleblind, randomized, placebo-controlled phase 2 trial. Eur Heart J 2016;37:2406-2413. 